\title{
Regression of viral pathogen indicators due to improvement of hygiene protocols on boots in a bovine farm
}

\author{
Satoru TAKAHASHI ${ }^{1) \#}$, Md. Amirul HASAN ${ }^{2) \#, ~ M a r i k o ~ I T O ' 1), ~ M i y u k i ~ K O M U R A ~}{ }^{1)}$, \\ Chisato DAIO'), Mizuki ONO ${ }^{1)}$, Makiko YAMAGUCHI ${ }^{1)}$, Md. Shahin ALAM ${ }^{2}$, \\ Md. Humayun KABIR2), Yu MIYAOKA ${ }^{2)}$, Dany SHOHAM ${ }^{2,3)}$ and \\ Kazuaki TAKEHARA ${ }^{1,2) *}$ \\ 1)Laboratory of Animal Health, Department of Veterinary Medicine, Faculty of Agriculture, Tokyo University of \\ Agriculture and Technology, 3-5-8 Saiwai-cho, Fuchu-shi, Tokyo 183-8509, Japan \\ 2) Laboratory of Animal Health, Cooperative Division of Veterinary Sciences, Graduate School of Agriculture, \\ Tokyo University of Agriculture and Technology, 3-5-8 Saiwai-cho, Fuchu-shi, Tokyo 183-8509, Japan \\ 3)Bar-llan University, Begin-Sadat Center for Strategic Studies, Ramat Gan 5290002, Israel
}

J. Vet. Med. Sci.

82(12): 1793-1797, 2020

doi: 10.1292/jvms.20-0358

Received: 11 June 2020

Accepted: 7 October 2020

Advanced Epub:

15 October 2020

\begin{abstract}
Rotavirus A (RVA), bovine torovirus (BToV), bovine enterovirus (BEV) and bovine coronavirus (BCV) at a bovine farm in lbaraki prefecture were monitored by one-step multiplex reverse transcription polymerase chain reaction (RT-PCR), with the aim of confirming the reduction of "viral pathogen indicators". A total of 960 bovine fecal samples were collected from calves less than 2 month-old within the period from October 2016 to October 2018 every 2 months at the bovine farm. In each sampling, 40 samples were taken from calves 3 week-old or less, and 40 samples from calves over 3 week-old, in principle. At the end of September 2017, the farm introduced improvement of hygiene protocols on boots by exchanging boots and appropriate usage of a footbath at the entrance of calf sheds. In the comparison of the virus detection by RTPCR, prevalence of all 4 viruses was significantly reduced $(P<0.01)$ in calves 3 week-old or less after the improvement. The mortality of calves less than 2 month-old was also significantly reduced after the improvement of hygiene protocols. These data suggest that the proper control of boots at calf sheds is important, perhaps even vital, for rearing hygiene measures at bovine farms so as to attain substantial decrease in the prevalence of pathogens.
\end{abstract}

KEY WORDS: biosecurity enhancement, exchange of boots, footbath, multiplex RT-PCR, viral pathogen indicators for bovine

Neonatal calf diarrhea (NCD) is the most important cause of disease in calves less than one month old [4, 8]. Causative viral agents of calf deaths before weaning resulting prevalently from $\mathrm{NCD}$, are rotavirus A (RVA) and bovine coronavirus (BCV) [4, 8]. To control these infectious diseases, enhancement of biosecurity at domestic farms is the key all over the world. Two measures of high importance for improvement of hygiene protocols on boots are exchanging boots at the entrance of each domestic animal shed and proper usage of footbath containing disinfectants. Given that proper usage of disinfectants is a key for enhancing biosecurity, "The Disinfection Handbook for the Field of Livestock" was published in February 2019 through Japan Livestock Industry Association [17], while this move was preceded in April 2018 (for the first time in 67 years) [13] and in December 2018 [15] (following classical swine fever outbreaks in Japan [14]) by revised and reinforced instructions, as set by MAFF.

Quaternary ammonium compounds (QACs) are common disinfectants at livestock farms, but their activities are normally reduced by organic material contamination and low temperature $[7,11]$. Pathogen inactivation efficacy of QAC was synergistically enhanced with food additive-grade calcium hydroxide $\left(\mathrm{FdCa}(\mathrm{OH})_{2}\right)[1,2,10]$. However, even while using $\mathrm{QAC}$ and $\mathrm{FdCa}(\mathrm{OH})_{2}$ mixture, it took more than 3 min to inactivate pathogens on abiotic carriers (rubber, plastic or steel) [1,2], and this suggests that changing boots at each shed seems to be better than dipping boots in a footbath, including in bovine farms. It was also suggested that boots should be kept for more than $3 \mathrm{~min}$ in $\mathrm{QAC}$ and $\mathrm{FdCa}(\mathrm{OH})_{2}$ mixture, because the mixture could inactivate nonenveloped viruses as well as enveloped viruses [1,18].

In the present research, in order to monitor bovine farm biosecurity level, RVA, bovine torovirus (BToV), bovine enterovirus

*Correspondence to: Takehara, K.: takehara@cc.tuat.ac.jp

\#These authors contributed equally to this work.

(O2020 The Japanese Society of Veterinary Science

This is an open-access article distributed under the terms of the Creative Commons Attribution Non-Commercial No Derivatives (by-nc-nd) License. (CC-BY-NC-ND 4.0: https://creativecommons.org/licenses/by-nc-nd/4.0/) 


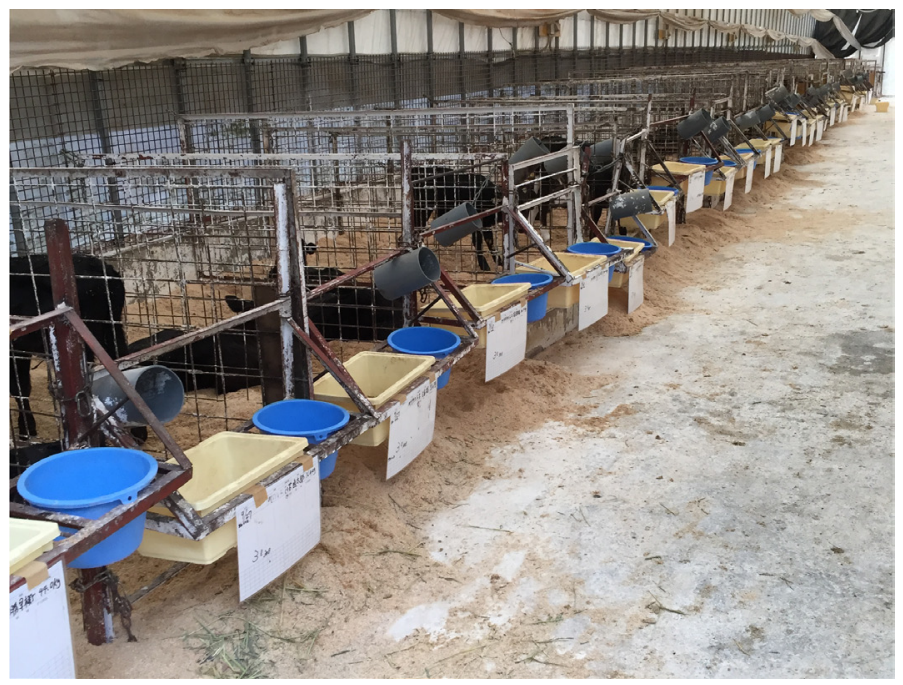

Fig. 1. Calf hatch. Each calf was kept in a calf hatch separately. All hatches were partitioned by a $20 \mathrm{~cm}$ square fence and connected to each other.

(BEV) and BCV were selected as "viral pathogen indicators", because these viruses account for the etiology of diarrhea, which causes considerable economic loss for bovine farms [3, 8, 12, 16, 19], and were prevalent in bovine farms in Japan [20]. All of those four viruses were also detected in farm A in Ibaraki prefecture [20]. Our previous results revealed that RVA was the primary agent among the positive samples obtained at the age of 3 weeks or below, while BEV was the primary among those obtained at an age over 3 weeks [20]. So in the present study, fecal samplings were separated by the age of calves (3 weeks or below and over 3 weeks).

In the present study, these four viruses were used as viral pathogen indicators and their prevalence in farm A alongside with the mortality of calves therein were compared before and after the improvement of hygiene protocols on boots at the entrance of calf sheds, for 2 years.

\section{MATERIALS AND METHODS}

\section{Farm and hygiene protocols on boots}

The study was conducted from October 2016 to October 2018 at a dairy farm in which around 120 calves (Japanese black or crossbred of Japanese black and Holstein) were produced monthly. Calves were transferred into individual calf hatches in calf sheds right after their birth and reared until two months of age in the same hatch. Each calf shed had around 60-80 hatches that were partitioned by metal fencing with $20 \mathrm{~cm}$ square grid (Fig. 1).

Before October 2017, the farm staffs wore the same boots on their work at different calf shed. Boots were disinfected for five seconds in a foot bath containing a 1,000-fold diluted combined chlorine disinfectant at the entrance of each calf shed, while the dilution was higher than 100 -fold, which is indicated in the manufacturer's instructions. At the end of September 2017, the protocols on boots hygiene were revised (Fig. 2). The farm staffs were required to change from their boots to the boots exclusively used in the shed at the entrance of each calf shed. Afterwards, the shed-exclusive boots were obligatorily washed and disinfected in a footbath containing the QAC (Rontect ${ }^{\circledR}$, Scientific Feed Laboratory Co., Ltd., Tokyo, Japan), diluted 1:500 with tap water and added $\mathrm{FdCa}(\mathrm{OH})_{2}$ powder (Fine Co., Ltd., Tokyo, Japan) at the final concentration of $0.17 \%$ at the exit of each calf shed [1, 2, 10].

\section{Sampling}

A total of 960 fecal samples were collected from calves at 1 to 8 weeks of age from October 2016 to October 2018, at intervals of two months. At each sampling, around 40 samples were collected from calves at three weeks of age or younger, as well as from calves older than three weeks of age (Table 1). A total of 560 and 400 samples collected from October 2016 to October 2017 and from December 2017 to October 2018 were considered as samples collected before and after the improvement of hygiene protocols and practice on boots, respectively (Tables 1 and 2). Fecal samples were kept cool during the shipment from the farm to the laboratory and stored at $-20^{\circ} \mathrm{C}$.

\section{RNA extraction and one-step multiplex RT-PCR}

Total RNA was extracted using ISOGEN-LS (Nippon Gene Co., Ltd., Tokyo, Japan) from supernatants of 10\% fecal homogenates and tested for RVA, BToV and BCV genes by one-step multiplex RT-PCR using PrimeScript One Step RT-PCR Kit ver.2 (Takara Bio Inc., Kusatsu, Japan), as described previously [20]. The PCR products were visualized on 1.5\% agarose gels stained with ethidium bromide. The estimated sizes of amplified products were 928 base pears (bp) for RVA, 651 bp for BoTV, 483 bp for BEV and $407 \mathrm{bp}$ for BCV [20]. 

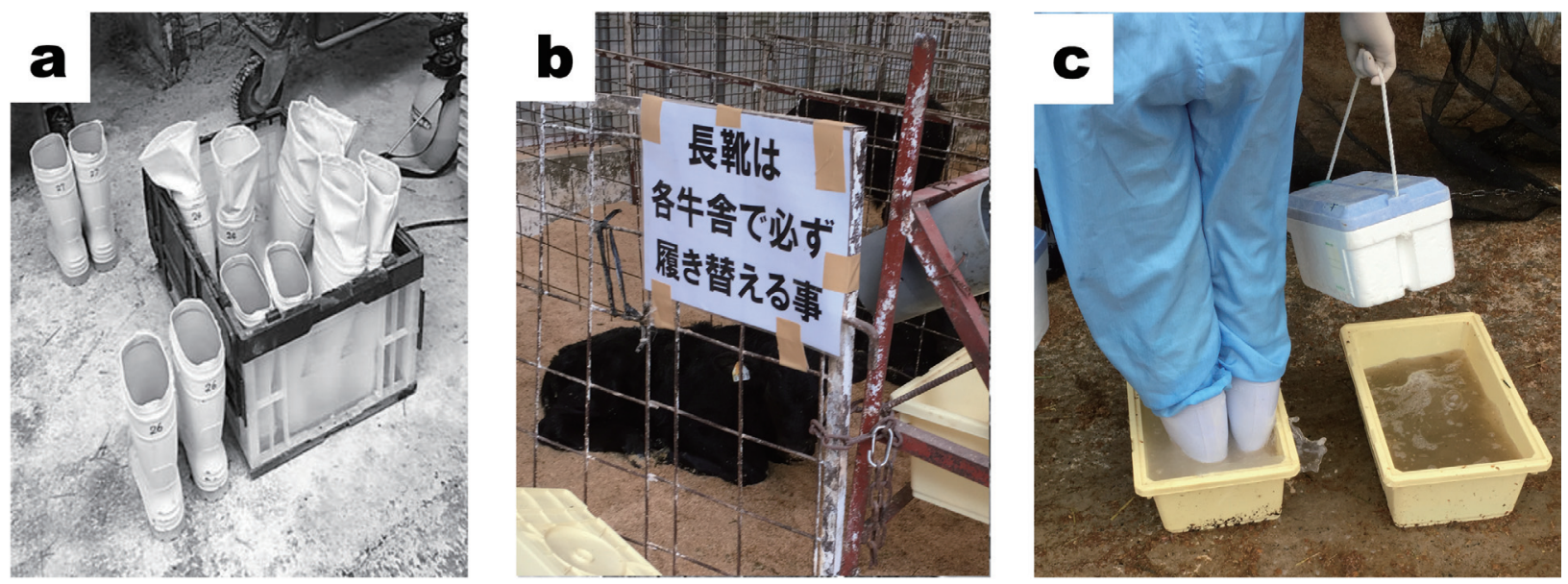

Fig. 2. Practicality of improving the hygiene protocols on boots. At the entrance of each calf shed, all staffs were required to change their boots to the boots destined only for each calf shed, specifically. a) Boots for the calf shed. b) A panel saying "Change your boots at the entrance of each calf shed". c) After use the boots inside the shed, the used boots were washed in a footbath containing water (left), then immersed in a footbath containing disinfectants (right) until next usage.

Table 1. Comparison of virus detection rates (\%) before and after improvement of hygiene protocols on boots, in reference to calves at different age groups

\begin{tabular}{|c|c|c|c|c|}
\hline & \multicolumn{2}{|c|}{ Calves at three weeks of age or younger } & \multicolumn{2}{|c|}{ Calves over three weeks of age } \\
\hline & Before $(\mathrm{n}=256)$ & After $(n=198)$ & Before $(n=304)$ & After $(n=202)$ \\
\hline RVA & 39.1 & $22.7 * *$ & 13.8 & 10.4 \\
\hline BToV & 8.2 & $1.0 * *$ & 11.2 & $4.0 * *$ \\
\hline $\mathrm{BEV}$ & 28.9 & $8.6^{* *}$ & 56.6 & $16.8 * *$ \\
\hline BCV & 23.4 & $8.1^{* *}$ & 33.2 & 35.6 \\
\hline
\end{tabular}

The total number of samples of calves of three weeks of age or younger before and after the improvement of hygiene protocols on boots, was 256 and 198, respectively. The total number of samples of calves over three weeks of age before and after the improvement was 304 and 202, respectively. RVA: Rotavirus A, BToV: bovine torovirus, BEV: bovine enterovirus, BCV: bovine coronavirus. **The significance of difference compared with the period preceding the improvement of hygiene protocols $(P<0.01)$.

\section{Mortality of calves less than two months old}

Total numbers of dead calves less than two months of age were recorded every month during the study period. Mortality was calculated by dividing the total number of dead calves less than two months old in the designated month by the total number of calves less than one month old at the end of the previous month and the total number of births in the designated month.

\section{Statistical analysis}

Welch's $t$-test was performed using Excel 2013 to compare the virus detection rates before and after improvement of hygiene protocols on boots, which pertain to the age-related and seasonal dynamics, respectively. A significant difference was considered at the level of $P<0.05$ or $P<0.01$. In the present study, four seasons were defined as spring from March to May, summer from June to August, autumn from September to November, and winter from December to February. The mortality of calves less than 2 monthold from November 2016 to October 2018 was also compared in reference to before and after improvement.

\section{RESULTS}

Comparison of virus detection rates before and after improvement of hygiene protocols on boots, in reference to calves at different age groups

In Table 1, age related dynamics of the targeted viruses was summarized. In calves at three weeks of age or younger, before the improvement of hygiene protocols, RVA prevalence of 39.1\% was the highest in the 4 targeted viruses, followed by BEV (28.9\%), $\mathrm{BCV}(23.4 \%)$ and $\mathrm{BToV}(8.2 \%)$. After the improvement, RVA was still bit high (22.7\%), however, all 4 viruses detection rates were reduced significantly $(P<0.01)$. On the contrary, in calves over three weeks of age, before the improvement, BEV prevalence of $56.6 \%$ was the highest and followed by BCV (33.2\%), RVA (13.8\%) and BToV (11.2\%). After the improvement, the prevalence of BEV and BToV was significantly reduced $(P<0.01)$ and RVA detection over three weeks of age was also reduced, though the reduction was not significant. $\mathrm{BCV}$ prevalence increased but not significantly. 
Table 2. Seasonal comparison of virus detection rates (\%) in calves, before and after the improvement of hygiene protocols on boots

\begin{tabular}{|c|c|c|c|c|c|c|c|c|c|c|}
\hline & \multicolumn{2}{|c|}{ Spring } & \multicolumn{2}{|c|}{ Summer } & \multicolumn{2}{|c|}{ Autumn } & \multicolumn{2}{|c|}{ Winter } & \multicolumn{2}{|c|}{ Total } \\
\hline & $\begin{array}{l}\text { Before } \\
(\mathrm{n}=80)\end{array}$ & $\begin{array}{c}\text { After } \\
(\mathrm{n}=80)\end{array}$ & $\begin{array}{c}\text { Before } \\
(\mathrm{n}=160)\end{array}$ & $\begin{array}{c}\text { After } \\
(\mathrm{n}=80)\end{array}$ & $\begin{array}{c}\text { Before } \\
(\mathrm{n}=160)\end{array}$ & $\begin{array}{c}\text { After } \\
(\mathrm{n}=80)\end{array}$ & $\begin{array}{c}\text { Before } \\
(\mathrm{n}=160)\end{array}$ & $\begin{array}{c}\text { After } \\
(\mathrm{n}=160)\end{array}$ & $\begin{array}{c}\text { Before } \\
(\mathrm{n}=560)\end{array}$ & $\begin{array}{c}\text { After } \\
(\mathrm{n}=400)\end{array}$ \\
\hline RVA & 17.5 & $35.0 *$ & 26.9 & $0.0^{* *}$ & 35.6 & $5.0 * *$ & 17.5 & 21.3 & 25.4 & 16.5 \\
\hline BToV & 26.3 & $0.0^{* *}$ & 7.5 & 2.5 & 4.4 & $0.0^{* *}$ & 9.4 & 5.0 & 9.8 & 2.5 \\
\hline BEV & 47.5 & $10.0 * *$ & 35.0 & $21.3 *$ & 40.0 & $11.3 * *$ & 55.0 & $10.6 * *$ & 43.9 & 12.8 \\
\hline BCV & 33.8 & 30.0 & 15.0 & 12.5 & 20.6 & $7.5^{* *}$ & 48.1 & $30.0 * *$ & 28.8 & 22.0 \\
\hline
\end{tabular}

RVA: Rotavirus A, BToV: bovine torovirus, BEV: bovine enterovirus, BCV: bovine coronavirus. ${ }^{*}$ The significance of difference compared with the period before the improvement of hygiene protocols $(P<0.05),{ }^{* *}$ The significance of difference compared with the period preceding the improvement $(P<0.01)$.

Table 3. Mortality (\%) of calves less than 2 months-old before and after improvement of hygiene protocols

\begin{tabular}{|c|c|c|c|c|c|c|c|c|c|c|c|c|c|}
\hline \multirow{2}{*}{ Period } & \multicolumn{12}{|c|}{ Month } & \multirow{2}{*}{ Average } \\
\hline & Nov. & Dec. & Jan. & Feb. & Mar. & Apr. & May & Jun. & Jul. & Aug. & Sep. & Oct. & \\
\hline Before improvement & 3.75 & 1.32 & 1.00 & 0.98 & 1.37 & 2.78 & 1.55 & 1.21 & 1.75 & 0.58 & 0.83 & 1.03 & 1.51 \\
\hline After improvement & 0.36 & 0.74 & 0.37 & 0.00 & 0.32 & 0.00 & 0.00 & 0.44 & 0.00 & 0.33 & 0.68 & 0.33 & 0.30 ** \\
\hline
\end{tabular}

**The significance of difference of the average mortality compared with the period preceding the improvement $(P<0.01)$.

Seasonal comparison of virus detection rates in calves between before and after improvement of hygiene protocols on boots

In Table 2, seasonal dynamics of the targeted viruses was summarized. In spring, before improvement, BEV prevalence was highest (47.5\%), followed by BCV (33.8\%), BToV (26.3\%), RVA (17.5\%). After improvement, the prevalence of BEV and BToV decreased significantly, but RVA prevalence increased significantly. In summer, before improvement, BEV was the most prevalent (35.0\%), followed by RVA, BCV and BToV, but after the improvement, RVA and BEV decreased significantly. In autumn, before improvement, BEV was the most common (40.0\%), followed by RVA (35.6\%), BCV and BToV, but after the improvement, the prevalence of all viruses was significantly reduced $(P<0.01)$. In winter, before the improvement, BEV had the highest prevalence (55.0\%), followed by BCV (48.1\%), RVA (17.5\%) and BToV. After improvement, the prevalence of BEV and BCV decreased significantly $(P<0.01)$.

\section{Overall decrease of mortality in calves younger than two months old after improvement of hygiene protocols on boots}

Mortality of calves less than 2 months-old before and after improvement period, namely from November 2016 to October 2017 and from November 2017 to October 2018, respectively, was compared. As shown in Table 3, mortality at each month was reduced and the average mortality was significantly reduced from $1.51 \%$ to $0.30 \%$ after the improvement $(P<0.01)$. Before and after improvement, mortality percent difference in spring was $1.79 \%$; followed by autumn $-1.41 \%$; summer $-0.79 \%$ and winter $-0.73 \%$.

\section{DISCUSSION}

RVA, BToV, BEV and BCV account for viral etiology of diarrhea, which causes considerable economic loss for bovine farms [3, $12,16,19]$. Especially, RVA and BCV are the primary causes for NCD and calves sometimes experienced mixed infection by these viruses $[4,8]$. Mixed infections usually make the disease worse than a single infection. BCV and BEV were detected continuously for several weeks in the same calves, however, RVA was detected only for several days [5, 6, 20].

As shown in Table 1, detection rates of the four viruses were significantly reduced in the younger calves and detection rates of $\mathrm{BToV}$ and BEV were also significantly reduced in the older calves after improvement of hygiene protocols. These data suggest that the reduction of presence of these four viral pathogen indicators in younger calves contributed the decrease in mortality of calves (Table 3).

In bovine farms, exchange of boots is not mandatory for the Standards of Rearing Hygiene Management in Japan. Most farms use foot baths at the entrance of sheds, however, the pathogen inactivation efficacy of the foot baths is suspicious.

In the present study, farm A introduced the improvement of hygiene protocols on boots by exchanging boots and appropriate usage of a footbath at the entrance of calf sheds as shown in the section of Materials and Methods (Fig. 2). There might be some seasonal differences of the prevalence of viruses, however, continuous monitoring over four seasons for two years, demonstrated that after the improvement of hygiene protocols, the prevalence of all viruses was significantly reduced in calves aged 3 week-old or less (Table 2). This fact means that the improvement of hygiene protocols of boots could reduce the virus contamination of calf sheds. Of course, some detection of viruses still continued, yet, the detection rates of the viruses were significantly decreased. These lowered detection rates may probably also correlate with the significantly reduced mortality in calves less than 2 months of age after improvement of hygiene protocols, as shown in Table 3. The staffs of farm A also recognized that comparison of the 
situation before and after improvement of hygiene protocols showed that: 1) the number of dead calves decreased, 2) the number of treated individuals related to diarrhea was also decreased, 3) even if treated, the treatment period was shortened.

Inactivation of pathogens on rubber coupons required more than $3 \mathrm{~min}[1,2]$. It was also demonstrated that slaked lime or alkaline agents in powder conditions are not highly alkaline, and that after adding water to the powders, these materials can be converted into highly alkaline ones [9]. This means that these powders cannot be used as footbath disinfectants, because it takes more than $3 \mathrm{hr}$ to inactivate pathogens in the feces that may attach to sole of boots [9]. In farm A, after improvement of hygiene protocols, foot baths at the exit of each calf shed were filled with diluted QAC added $\mathrm{FdCa}(\mathrm{OH})_{2}$ powder at the final concentration of $0.17 \%$. It was demonstrated that pathogen inactivation efficacy of QAC was synergistically enhanced with food additive-grade calcium hydroxide $\left(\mathrm{FdCa}(\mathrm{OH})_{2}\right)[1,2,10]$.

Our present data and information from farm A suggest that proper control of boots at bovine sheds, especially for calves, is important for rearing hygiene measures at bovine farms. To maintain the high biosecurity conditions, it is vital to recognize the importance of sharing information on detection frequency of pathogens with farm staffs.

To control infectious diseases, including highly pathogenic avian influenza, CSF and foot and mouth disease, "Re-enforcement of the Standards of Rearing Hygiene Management" is important. Especially, the improvement of hygiene protocols through exchanging boots and appropriate usage of a footbath at the entrance of animal sheds seem to be one of the essential measures for the control of infectious diseases.

POTENTIAL CONFLICTS OF INTEREST. The authors have nothing to disclose.

ACKNOWLEDGMENTS. The authors thank farm A for giving a chance to collect feces and for the effort to improvement of hygiene protocols one of the tools to enhance biosecurity in the farm. This study was supported in part by JSPS KAKENHI Grant16K08004.

\section{REFERENCES}

1. Alam, M. S., Takahashi, S., Ito, M., Komura, M., Ono, M., Daio, C., Sangsriratanakul, N., Shoham, D., Alam, J. and Takehara, K. 2018. Virucidal efficacy of a quaternary ammonium compound with food additive-grade calcium hydroxide toward avian influenza virus and Newcastle disease virus on abiotic carriers. Avian Dis. 62: 355-363. [Medline] [CrossRef]

2. Alam, M. S., Takahashi, S., Ito, M., Komura, M., Suzuki, M., Sangsriratanakul, N., Shoham, D. and Takehara, K. 2018. Bactericidal efficacy of a quaternary ammonium compound with food additive grade calcium hydroxide toward Salmonella Infantis and Escherichia coli on abiotic carriers. J. Vet. Med. Sci. 80: 1482-1489. [Medline] [CrossRef]

3. Blas-Machado, U., Saliki, J. T., Sánchez, S., Brown, C. C., Zhang, J., Keys, D., Woolums, A. and Harvey, S. B. 2011. Pathogenesis of a bovine enterovirus-1 isolate in experimentally infected calves. Vet. Pathol. 48: 1075-1084. [Medline] [CrossRef]

4. Cho, Y. I., Han, J. I., Wang, C., Cooper, V., Schwartz, K., Engelken, T. and Yoon, K. J. 2013. Case-control study of microbiological etiology associated with calf diarrhea. Vet. Microbiol. 166: 375-385. [Medline]

5. Cho, Y. I. and Yoon, K. J. 2014. An overview of calf diarrhea - infectious etiology, diagnosis, and intervention. J. Vet. Sci. 15: 1-17. [Medline]

6. Cliver, D. O. and Bohl, E. H. 1962. Isolation of enteroviruses from a herd of dairy cattle. J. Dairy Sci. 45: 921-925.

7. Gerba, C. P. 2015. Quaternary ammonium biocides: efficacy in application. Appl. Environ. Microbiol. 81: 464-469. [Medline]

8. Gomez, D. E. and Weese, J. S. 2017. Viral enteritis in calves. Can. Vet. J. 58: 1267-1274. [Medline]

9. Hakim, H., Toyofuku, C., Ota, M., Suzuki, M., Komura, M., Yamada, M., Alam, M. S., Sangsriratanakul, N., Shoham, D. and Takehara, K. 2017. Accuracy of the evaluation method for alkaline agents' bactericidal efficacies in solid, and the required time of bacterial inactivation. J. Vet. Med. Sci. 79: 244-247. [Medline] [CrossRef]

10. Ito, M., Alam, M. S., Suzuki, M., Takahashi, S., Komura, M., Sangsriratakul, N., Shoham, D. and Takehara, K. 2018. Virucidal activity of a quaternary ammonium compound associated with calcium hydroxide on avian influenza virus, Newcastle disease virus and infectious bursal disease virus. J. Vet. Med. Sci. 80: 574-577. [Medline] [CrossRef]

11. Jang, Y., Lee, K., Yun, S., Lee, M., Song, J., Chang, B. and Choe, N. H. 2017. Efficacy evaluation of commercial disinfectants by using Salmonella enterica serovar Typhimurium as a test organism. J. Vet. Sci. 18: 209-216. [Medline] [CrossRef]

12. Kuwabara, M., Wada, K., Maeda, Y., Miyazaki, A. and Tsunemitsu, H. 2007. First isolation of cytopathogenic bovine torovirus in cell culture from a calf with diarrhea. Clin. Vaccine Immunol. 14: 998-1004. [Medline] [CrossRef]

13. Ministry of Agriculture Forestry and Fisheries. About the notice matter for incineration, landfill and disinfection based on Act on Domestic Animal Infectious Disease Control. http://www.maff.go.jp/j/syouan/douei/katiku_yobo/attach/pdf/index-123.pdf [accessed on May 1, 2020].

14. Ministry of Agriculture Forestry and Fisheries. Classical swine fever in Japan. http://www.maff.go.jp/j/syouan/douei/csf/ [accessed on May 1, 2020].

15. Ministry of Agriculture Forestry and Fisheries. About re-enforcement of rearing hygiene management standard for classical swine fever, African swine fever and avian influenza. http://www.maff.go.jp/j/syouan/douei/katiku_yobo/k_shiyou/attach/pdf/index-59.pdf [accessed on May 1, 2020].

16. Pastoret, P. P., Schwers, A., Vanden Broecke, C. and Werenne, J. 1984. Epizootiology of rotavirus diarrhoea in the bovine species. Rev. Sci. Tech. 3: 843-853. [Medline] [CrossRef]

17. Takehara, K. 2019. The Disinfection Handbook for the Field of Livestock, Japan Livestock Industry Association, Tokyo.

18. Thammakarn, C., Ishida, Y., Suguro, A., Hakim, H., Nakajima, K., Kitazawa, M. and Takehara, K. 2015. Inhibition of infectious bursal disease virus transmission using bioceramic derived from chicken feces. Virus Res. 204: 6-12. [Medline] [CrossRef]

19. Tsunemitsu, H., Smith, D. R. and Saif, L. J. 1999. Experimental inoculation of adult dairy cows with bovine coronavirus and detection of coronavirus in feces by RT-PCR. Arch. Virol. 144: 167-175. [Medline] [CrossRef]

20. Yamada, M., Kubota, K., Takahashi, S., Toyofuku, C., Hakim, H., Alam, M. S., Hasan, M. A., Shoham, D. and Takehara, K. 2020. Longitudinal and cross-sectional detection of four bovine enteric viruses by multiplex- reverse transcription polymerase chain reaction: Identification of possible indicator viruses to assess biosecurity level at bovine farms. J. Vet. Med. Sci. 82: 314-319. [Medline] [CrossRef] 